\title{
NUTRITIONAL RICKETS IN CHILDREN (CASE REPORT)
}

\author{
Chaychenko T. , Shulha.$_{.}{ }^{2}$, Kharkova M. ${ }^{1}$, Rybka O. ${ }^{1}$, Buginskaya $N .{ }^{1}$, Chercun $A .^{2}$ \\ ${ }^{1}$ Kharkiv National Medical University, Ukraine \\ ${ }^{2}$ Municipal nonprofit enterprise of the Kharkiv Regional Council \\ "Regional children clinical hospital"
}

\begin{abstract}
Nutritional rickets (NR) caused by vitamin D and/or dietary calcium deficiency remains a significant global, public health problem. The main causes of NR are discussed with a focus on the investigations, management and prophylaxis by the Global Consensus Recommendations on Prevention and Management of NR (2016).

The article presents a clinical case of NR in a girl aged 4 years and 3 months admitted to our hospital with severe deformation of low extremities. She was found to have vitamin D-deficient state with extremely high alkaline phosphatase, suggestive for massive bone resorption. NR was diagnosed following comprehensive examination and therapy according to the protocol was initiated.

Conclusions: NR rate tends to the incline in both low-income and industrialized countries, which requires special attention of pediatricians to the classical clinical presentation with particular focus on the risk group.
\end{abstract}

Key words: Nutritional rickets, vitamin D, children, deformity of extremities.

Nutritional rickets (NR) is still the most common form of growing bone disease despite of the efforts of health care providers to reduce the incidence of the disorder. Recent evidence suggests that in addition to its short- or long-term effects on skeletal development, vitamin D (VitD) deficiency during infancy may predispose the patient to diseases such as diabetes mellitus, cancer and multiple sclerosis [1].

Rickets is a childhood bone disorder in which bones soften and become prone to fractures and deformity. There was an opinion that it is a rare condition in industrialized countries, but fairly common in some developing countries [2]. Meantime, the current scientific reports give an idea that this problem is pretty common at the moment in all urbanized countries [3] both in children and adults due to different predisposing factors and life style [4].

Corresponding Author:

Tetyana Chaychenko, $\mathrm{MD}, \mathrm{PhD}$,

Professor of Department of Pediatrics No. 1

and Neonatology of Kharkiv National

Medical University, Ukraine.

E-mail: tatyana.chaychenko@gmail.com
According to the recent data [5], statistics in Ukraine is as follows:

$-95 \%$ of Ukrainians are VitD deficient;

$-73 \%$ of pregnant and lactating females are VitD deficient on multivitamin supplementation.

$-88.9 \%$ allergic patients are VitD deficient; $-53.3 \%$ asthmatic children are VitD deficient.

Definition and Diagnosis of Nutritional

\section{Rickets}

Nutritional rickets (NR), a disorder of defective chondrocyte differentiation and mineralization of the growth plate and defective osteoid mineralization, is caused by vitamin D deficiency and/or low calcium intake in children [6].

Children are predisposed to rickets in case of $\mathrm{Ca} / \mathrm{P}$ deficiency due to fast growth, high speed of skeleton remodeling secondary to underdevelopment of metabolic pathways. Depending on its mechanism, rickets is divided into several groups: Ca-deficient, P-deficient, Vitamin D-deficient [7].

Exogenous causes of VitD deficiency [8] are:

- Low consumption of VitD-containing food (yolk, fish, liver, milk, caviar, butter).

It is worth mentioning that consumption of natural vitamin D sources such as oil-rich fish, 
fortified foods and supplements is influenced by cultural dietary practices and national policies. Plasma 25(OH)D concentrations were lower in vegetarians and vegans than in meat and fish eaters in a UK study [9].

- Low insolation time that causes problems with a conversion of 7-dehydrocholesterol to the cholecalciferol in the skin (fig. 1) well be both predisposed to different form of rickets genetically and have $\mathrm{Ca} / \mathrm{P}$ metabolism influenced by nutritional factors [14].

Risk groups for nutritional rickets are:

- Premature and low birth weight newborns, tweens;

- Patients with malabsorption (celiac disease, enteropathy, etc.)

\section{VITAMIN D METABOLISM}

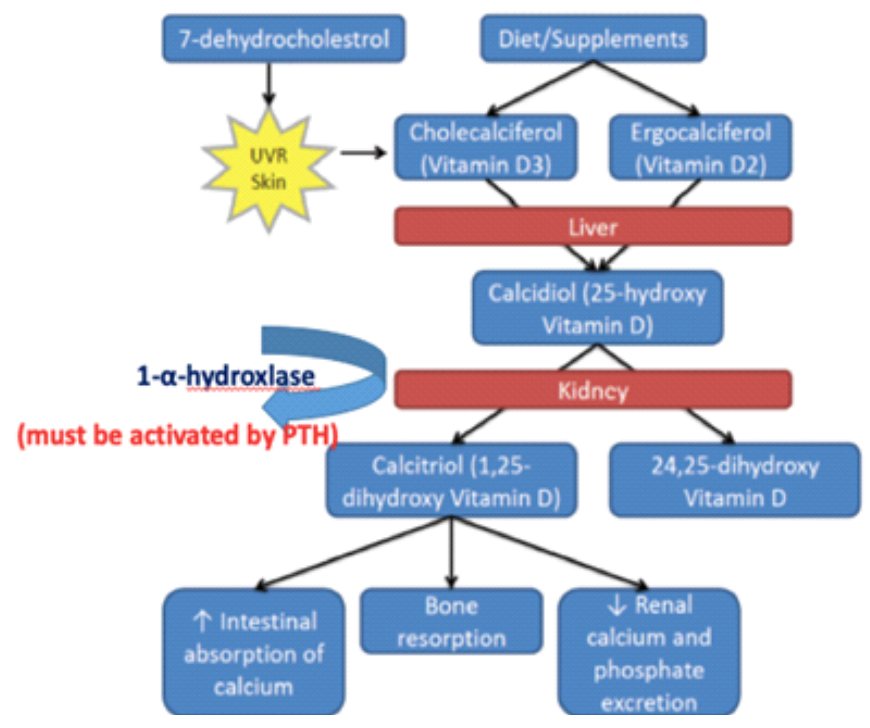

Fig. 1. Vitamin D metabolism in the human body 10 [12]

Personal characteristics, such as skin pigmentation, age, style of clothing, use of sunscreen, physical and outdoor activity and sun exposure behavior, can prevent or promote vitamin D synthesis and influence vitamin D status [10]. Interestingly that melanin efficiently absorbs UVB photons and people with increased skin melanin pigmentation (darker skin) require longer exposures to sunlight to produce the same amount of vitamin D compared with light-skinned people. Thus, relevant ethnicities are under the risk of VITD-deficiency [11].

Endogenous causes of VitD deficiency [13] are:

- Problems with intestinal calcium absorption due to malabsorption syndromes, biliary obstruction etc.);

- Impaired hydroxylation of inactive VitD 2 to active VitD3 in kidneys and liver (due to chronic diseases of the mentioned organs or genetic defects);

- Impaired balance of $\mathrm{Ca} / \mathrm{P}$ absorption and excretion;

- Impaired VitD receptors function

It is worth taking into the account that some ethnicities, such as Middle East population, may
- Patients on anticonvulsants;

- Prolonged immobilization (palsy, orthopedic problems, traumas, etc.)

- Patients with a chronic liver and biliary tract diseases

- Infants on the non-adapted formula or animal milk feeding.

Classification of vitamin D status, based on serum 25OHD (VitD2) levels [6]:

- Sufficiency, $>50 \mathrm{nmol} / \mathrm{l}$;

- Insufficiency, 30-50 nmol/1;

- Deficiency, $<30 \mathrm{nmol} / \mathrm{l}$.

The diagnosis of nutritional rickets is made on the basis of history taking, physical examination and biochemical testing, and is confirmed by radiography [6].

Diagnosis of rickets should be based on the identification of characteristic manifestations of the skeletal system - signs of osteomalacia such as craniotabes (fig. 2), osteoid hyperplasia (fig. 3) and deformity of extremities (fig. 4).

Differential diagnosis of the rickets should be made by the comparison of laboratory findings (tab.1). 


\section{CASE STUDY}

A girl aged 4 years and 3 months was admitted to the clinic with the only presenting complaint of low extremities deformity (fig. 4).

The child was born from the fourth term pregnancy ( 39 weeks, by caesarean section due to the scar on the uterus. Birth weight was $2360 \mathrm{~g}$ and length was $48 \mathrm{~cm}$, which were suggestive for intrauterine growth retardation: an asymmetric

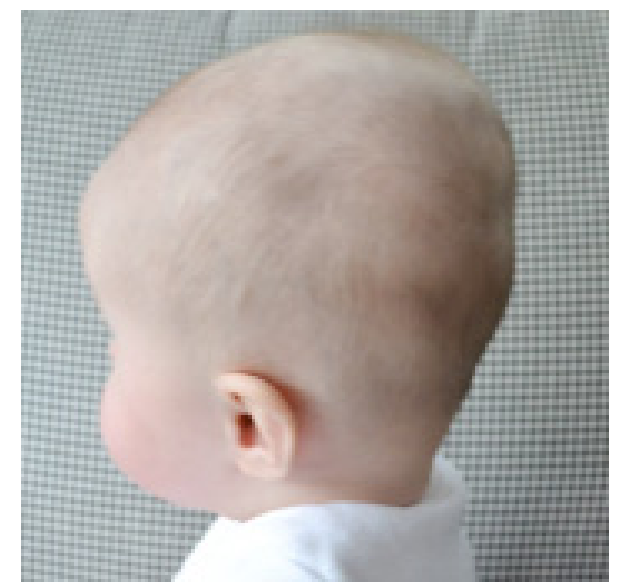

Fig. 2. Craniotabes [15]; Source: 2.bp.blogspo
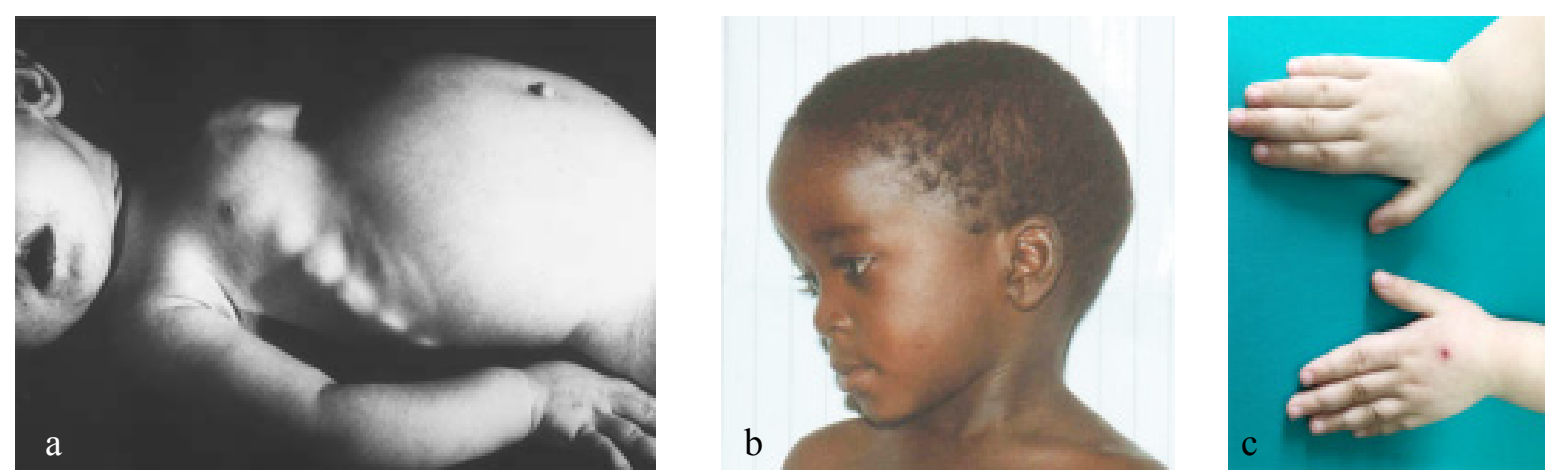

Fig. 3. Osteoid hyperplasia: a) Harrison sulcus and rosary [16]; b) Frontal bossing [17];

c) Swelling of the wrist and ankle joints
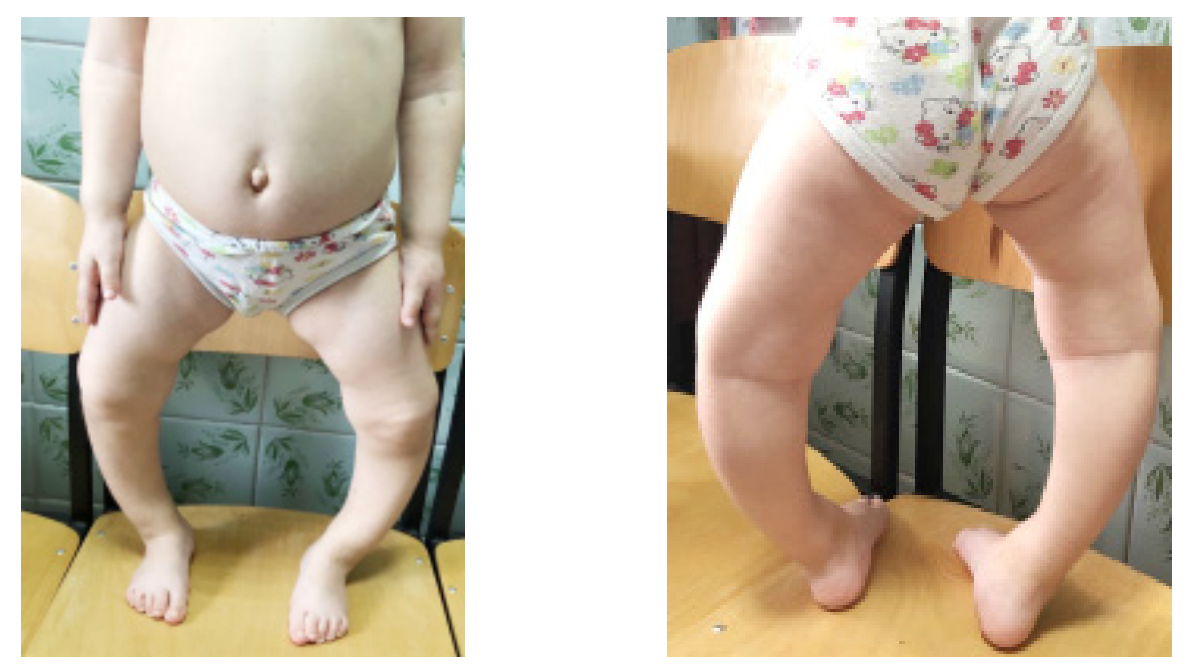

Fig. 4. Deformity of extremities 
Differential diagnosis of vitamin $D$ and calcium related disorders [18]

Table 1

\begin{tabular}{|c|c|c|c|c|c|}
\hline Diagnosis & $\mathrm{Ca}_{2}$ & $\mathrm{PO}_{4}$ & PTH & $25 \mathrm{OHD}$ & $1.25-\mathrm{OHD}$ \\
\hline Vitamin D-deficient rickets & $\downarrow N$ & $\downarrow$ & $\uparrow$ & $\downarrow$ & $\downarrow, N, \uparrow$ \\
\hline Vitamin D-dependent rickets & \multirow[b]{2}{*}{$\downarrow$} & \multirow[b]{2}{*}{$\downarrow$} & \multirow[b]{2}{*}{$\uparrow$} & \multirow[b]{2}{*}{$\mathrm{N}, \downarrow$} & \multirow[b]{2}{*}{$\downarrow$} \\
\hline $\begin{array}{l}\text { - type } 1 \text { (deficiency } \\
\text { of } 1 \alpha-h y d r o x y l a t i o n)\end{array}$ & & & & & \\
\hline $\begin{array}{l}\text { - type } 2 \text { (resistance } \\
\left.\text { to } 1.25-(\mathrm{OH})_{2} \mathrm{D}\right)\end{array}$ & $\downarrow$ & $\downarrow$ & $\uparrow$ & $\mathrm{N}, \downarrow$ & $N \uparrow$ \\
\hline $\begin{array}{l}\text { X-linked hypophosphataemic } \\
\text { rickets }\end{array}$ & $\mathrm{N}$ & $\downarrow$ & $\mathrm{N}$ & $\mathrm{N}$ & $\mathrm{N} \downarrow$ \\
\hline $\begin{array}{l}\text { Hypophosphataemic rickets } \\
\text { with hypercalciuria }\end{array}$ & $\mathrm{N}$ & $\downarrow$ & $\mathrm{N}$ & $\mathrm{N}$ & $\uparrow$ \\
\hline Tumour-induced rickets & $\mathrm{N}$ & $\downarrow$ & $\mathrm{N}$ & $\mathrm{N}$ & $\downarrow$ \\
\hline Renal osteodystrophy & $\mathrm{N} \downarrow$ & $\uparrow$ & $\uparrow \uparrow$ & $\mathrm{N}$ & $\mathrm{N} \downarrow$ \\
\hline Primary hyperparathyroidism & $\uparrow$ & $\downarrow$ & $\uparrow$ & $\mathrm{N}$ & $\mathrm{N} \uparrow$ \\
\hline Hypoparathyroidism & $\downarrow$ & $\uparrow$ & $\downarrow$ & $\mathrm{N}$ & $\downarrow \mathbf{N}$ \\
\hline Pseudohypoparathyroidism & $\downarrow$ & $\uparrow$ & $\uparrow$ & $\mathrm{N}$ & $\downarrow \mathbf{N}$ \\
\hline Vitamin D intoxication & $\uparrow$ & $\mathrm{N}$ & $\downarrow$ & $\uparrow$ & $\mathrm{N} \uparrow$ \\
\hline $\begin{array}{l}\text { Hypercalcemia } \\
\text { in granulomatous disorders }\end{array}$ & $\uparrow$ & $\mathrm{N}$ & $\downarrow$ & $\mathrm{N}$ & $\uparrow$ \\
\hline
\end{tabular}

Physical examination:

Weight: $14 \mathrm{~kg}$. Height: $85.3 \mathrm{~cm}$ (-3SD). Height could not be interpreted correctly due to markedly presented deformity of low extremities.

Puberty: Ax1 P1 Ma1 Me1 (Tanner 1)

Vital functions: T-36.6 C ${ }^{\circ}$, HR-90 bpm, RR-24 per min.

Skin and integumentary system: normal.

Lymphatic system - normal.

Bones and joints: Genu varum, rosary, swelling of the wrist and ankle joints.

Cardiovascular system - normal.

GIT: enlarged abdomen due to low muscle tone, palpation is painless, no enlargement of liver and spleen.

Stool and urination - normal.
Laboratory findings (tab. 2).

Results of the examination are suggestive for the appropriate both ionized and total calcium level with episodes of hypocalcemia in past history. High alkaline phosphatase level indicates that the blood calcium is a result of the massive bone resorption. Low calcium and phosphorus excretion are markers of the deficient state. PTH level is compensatory high. 25-OH VitD level is indicative for VitD-deficient state.

Diagnosis is Vitamin D Deficient rickets, active (E 55.0)

Treatment: Vitamin D supplementation 2000 IU/day together with oral $\mathrm{Ca} 500 \mathrm{mg} /$ day was started. The patient is under examination in orthopedic clinic with the purpose of further

Laboratory findings of the patient with extremities deformity

\begin{tabular}{|l|c|c|}
\hline \multicolumn{1}{|c|}{ Parameter } & Value & Reference range \\
\hline Total calcium & 2.59 & $2.2-2.7 \mathrm{mmol} / \mathrm{l}$ \\
\hline Ionized Ca & 1.26 & $1.16-1.32 \mathrm{mmol} / \mathrm{l}$ \\
\hline $\mathrm{P}$ & 2.32 & $1.29-2.26 \mathrm{mmol} / \mathrm{l}$ \\
\hline $\mathrm{Mg}$ & 1.0 & $0.66-1.03 \mathrm{mmol} / \mathrm{l}$ \\
\hline $\mathrm{Na}$ & 136.6 & $135-155 \mathrm{mmol} / \mathrm{l}$ \\
\hline $\mathrm{K}$ & 4.77 & $3.2-6.1 \mathrm{mmol} / \mathrm{l}$ \\
\hline $24-$ hour urine calcium excretion & 0.51 & $2.0-4.0 \mathrm{mmol} / \mathrm{day}$ \\
\hline 24-hour urine magnesium excretion & 0.57 & $4.94-119.7 \mathrm{mmol} / \mathrm{day}$ \\
\hline 24-hour urine phosphorus excretion & 8.1 & $12.9-42.0 \mathrm{mmol} / \mathrm{day}$ \\
\hline Parathyroid hormone & 73.1 & $15-65 \mathrm{pg} / \mathrm{ml}$ \\
\hline Alkaline phosphatase & 13000 & $1200-6300 \mathrm{nmol} / \mathrm{day}$ *I \\
\hline 25-OH Vitamin D & 7.28 & $<20 \mathrm{ng} / \mathrm{ml}-\mathrm{deficit}$ \\
\hline 1,25-OH Vitamin D & 60.3 & $19.9-79.3 \mathrm{pg} / \mathrm{ml}$ \\
\hline \hline
\end{tabular}


management strategy elaboration. Next scheduled visit with laboratory assessment - after 3 months of stable medication.

Treatment of rickets [6]

Dose of Vitamin D and Calcium for the Treatment of Nutritional Rickets

- For the treatment of Nutritional Rickets, the minimal recommended dose of vitamin $\mathrm{D}$ is $2,000 \mathrm{IU} /$ day $(50 \mu \mathrm{g})$ for a minimum of 3 months.

- Oral calcium, $500 \mathrm{mg} /$ day, either as dietary intake or supplement, should be routinely used in conjunction with vitamin $\mathrm{D}$ in the treatment regardless of age or weight.

Appropriate Route of Administration and Duration of Therapy

- Oral treatment, which more rapidly restores 25OHD levels than intramuscular treatment.

- For daily treatment, both D2 and D3 are equally effective.

- When single large doses are used, D3 appears to be preferable compared to $\mathrm{D} 2$ because the former has a longer half-life.

- Vitamin D treatment is recommended for a minimum of 12 weeks, recognizing that some children may require longer treatment duration.

Prevention of rickets [6]

Dietary Calcium Intake to Prevent Rickets

- For infants 0-6 and 6-12 months of age, the adequate calcium intake is 200 and $260 \mathrm{mg} /$ day, respectively.

- For children over 12 months of age, dietary calcium intake of $<300 \mathrm{mg}$ /day increases the risk of rickets independently of serum 25OHD levels.

- For children over 12 months of age, the panel recommends the following classification of dietary calciumintake:

- Sufficiency, $>500 \mathrm{mg} /$ day;

- Insufficiency, 300-500 mg/day;

- Deficiency, $<300 \mathrm{mg} /$ day.

Vitamin D Supplementation for the Prevention of Rickets and Osteomalacia

- $400 \mathrm{IU} /$ day $(10 \mu \mathrm{g})$ is adequate to prevent rickets and is recommended for all infants from birth to 12 months of age, independently of their mode of feeding.

- Beyond 12 months of age, all children and adults need to meet their nutritional requirement for vitamin $\mathrm{D}$ through diet and/or supplementation, which is at least $600 \mathrm{IU} /$ day $(15 \mu \mathrm{g})$, as recommended by the Institute of Medicine (IOM).

Target for Vitamin D Supplementation:

- In healthy children, routine 25OHD screening is not recommended, and consequently, no specific $25 \mathrm{OHD}$ threshold for vitamin D supplementation is targeted in this population.
Candidates for Preventative Vitamin D Supplementation beyond 12 Months of Age

In the absence of food fortification, vitamin D supplementation should be given to:

- Children with a history of symptomatic vitamin $\mathrm{D}$ deficiency requiring treatment.

- Children and adults at high risk of vitamin D deficiency with factors or conditions that reduce synthesis or intake of vitamin D.

Dietary Practices and Nutrient Intakes among Mothers Associated with Nutritional Rickets in Infants

- Maternal vitamin D deficiency should be avoided by ensuring that women of childbearing age meet intakes of $600 \mathrm{IU} /$ day recommended by the IOM.

- Pregnant women should receive $600 \mathrm{IU} /$ day of vitamin D, preferably as a combined preparation with other recommended micronutrients such as iron and folic acid.

Early Feeding, Supplementation, Complementary Feeding, and Nutrient Intake Associated with Rickets in Infants

- In addition to an intake of $400 \mathrm{IU} /$ day of vitamin $\mathrm{D}$, complementary foods introduced no later than 26 weeks should include sources rich in calcium.

- An intake of at least $500 \mathrm{mg} /$ day of elemental calcium must be ensured during childhood and adolescence.

Association of Sunlight Exposure with Nutritional Rickets

- Because ultraviolet B (UVB) rays trigger epidermal synthesis of pre-vitamin D 3, restricted exposure to sun increases the risk of vitamin D deficiency and NR.

- Environmental factors, such as latitude, season, time of day, cloud cover, and pollution affect the availability of UVB, whereas personal factors, such as time spent outdoors, skin pigmentation, skin coverage, age, body composition, and genetics affect the dose response of UVB exposure and circulating $25 \mathrm{OHD}$.

- No safe threshold of UV exposure allows for sufficient vitamin D synthesis across the population without increasing skin cancer risk.

Conclusions: NR rate tends to the incline in both low-income and industrialized countries that requires special attention of pediatricians to the classical clinical presentation with particular focus on the risk group. Proper timely prophylaxis and treatment with using appropriate dosages of VitD and Calcium are demanded so as to prevent severe bone deformity. 


\section{References:}

1. Ozkan, B. J. (2010). Clin Res Pediatr Endocrinol, 2(4), 137-143.

2. Brunner, S. B.A. (2017). Everything you need to know about rickets, Medical news today, 19.12.

3. Creo, A. L., Thacher, T. D., Pettifor, J. M., Strand, M. A., Fischer, P. R. (2017). Nutritional rickets around the world: an update, Paediatrics and International Child Health, 37:2, 84-98, DOI:10.1080/ 20469047.2016.1248170

4. Spiro, A., Buttriss, J. L. (2014). Vitamin D: An overview of vitamin D status and intake in Europe. Nutr Bull, 39(4), 322-350. doi: 10.1111/nbu.12108

5. (2016). Materialy Pervogo mezhdunarodnogo medicinskogo foruma "Deficit vitamina D - problema nacional'nogo i global'nogo masshtaba" [Materials of the First International Medical Forum "Vitamin D deficiency - a problem of national and global scale"].

6. Munns, C.F., Shaw, N., Kiely, M., Specker, B.L., Thacher, T.D, Ozono, K.,... Hogler, W. (2016). Global Consensus Recommendations on Prevention and Management of Nutritional Rickets, J Clin Endocrinol Metab, doi: 10.1210/jc.2015-217.

7. Malcev, S.V. (2008). To the discussion of rickets, "Pediatrics", volume 87, No. 2, 120-123.

8. Pettifor, J.M. (2004). Nutritional rickets: deficiency of vitamin D, calcium, or both? Am J Clin Nutr, 80(6 Suppl), 1725S-9S. doi: 10.1093/ajcn/80.6.1725S.

9. Crowe, F.L., Steur, M., Allen, N.E. (2011). Plasma concentrations of 25-hydroxyvitamin D in meat eaters, fish eaters, vegetarians and vegans: results from the EPIC-Oxford study. Public Health Nutrition, 14, 340-346.

10. Cashman, K.D., Kiely, M. (2014). Recommended dietary intakes for vitamin D: where do they come from, what do they achieve and how can we meet them? Journal of Human Nutrition and Dietetics, doi: $10.1111 /$ jhn.12226.

11. Holick, M.F. (2004). Sunlight and vitamin D for bone health and prevention of autoimmune diseases, cancers, and cardiovascular disease. American Journal of Clinical Nutrition, 80, 1678S-1688.

12. Holick, M.F. (1996). Vitamin D and bone health. J.Nutr, 126 (supp. 14), 1159S-1164S.

13. Majdannik, V.G. (2014). Klinicheskie rekomendacii po diagnostike, lecheniju i profilaktike vitamin d-deficitnogo rahita u detej [Clinical guidelines for the diagnosis, treatment and prevention of vitamin D deficiency rickets in children]. Kiev, p.58.

14. Giampiero I., Baroncelli, G. I., Bereket, A., Kholy, M. El., Aud?, L., Cesur, Y., Ozkan, B., Hochberg, Z. (2008). Rickets in the Middle East: Role of Environment and Genetic Predisposition, The Journal of Clinical Endocrinology \& Metabolism, Volume 93, Issue 5, 1743-1750, https://doi.org/10.1210/jc.2007-1413

15. https://gbistandart.ru/assets/f8e7163774.jpg

16. http://patologia.gabeents.com/data/Pathologic/images/banner_01.jpg

17. http://adc.bmj.com/content/89/8/781.full

18. Raine, J.E. Donaldson, M. D.C., Gregory, J. W., Savage, M. O., Hintz, R. L. (2005). Practical endocrinology and diabetes in hildren., (2nd ed). DOI: 10.1002 / 9780470994856.

Received: 17-Feb-2018

Accepted: 17-Mar-2019 